Bull. Mater. Sci., Vol. 4, Number 1, March 1982, pp. 47-51. $O$ Printed in India.

\title{
Structural, magnetic and electrical study of $\mathrm{MgCoMnO}_{4}$
}

\author{
S G JOSHI, D K KULKARNI and P V KHANDEKAR \\ Department of Physics, Institute of Science, Nagpur 440 001, India \\ MS received 9 April 1981 ; revised 10 June 1981
}

\begin{abstract}
A new compound $\mathrm{MgCoMnO}_{4}$ has been synthesised by the oxide method. It crystallizes in a tetragonal spinel structure with $a=8.30 \mathrm{~A}$ and $c=8.46 \mathrm{~A}$. The observed crystal symmetry is associated with the existence of $\mathrm{Mn}+3$ on the $B$ sites. The compound is $n$ type semi-conductor with activation energy $\Delta E=0.33 \mathrm{eV}$. The electrical properties show that it can be regarded as a properly substituted $\mathrm{MgMn}_{2} \mathrm{O}_{4}$ by $\mathrm{Co}^{+3}$ ions. It is paramagnetic with $C_{M} \geq 5.75$ and $\theta a=-160^{\circ} \mathrm{K}$. All these results show the ionic configuration of the compound as $\mathrm{Mg}+2[\mathrm{Co}+3 \mathrm{Mn}+3] \mathrm{O}_{4 i}$
\end{abstract}

Keywords. Spinel ; electrical conductivity ; Curie molar coñstant.

\section{Introduction}

Spinels containing transition metal (TM) ions exhibit remarkable electrical and magnetic properties which are governed by the valence state and the site distribution of the cations. When two or more types of TM ions are present in the spinel, complications arise due to several possible oxidation states and site preferences. However, the bulk distortion of the lattice can indicate the presence of certain TM ions, such as, $d^{4}\left(\mathrm{Mn}^{+3}\right)$ or $d^{9}\left(\mathrm{Cu}^{+2}\right)$. The $c / a$ ratio is suggestive of such distortive ions since their presence at the tetrahedral $(A)$ or the octahedral $(B)$ sites reduce or increase it.

A survey of literature on $\mathrm{ZnMnMeO}_{4}$, where $\mathrm{Me}=\mathrm{Cr}, \mathrm{Mn}, \mathrm{Fe}$ and $\mathrm{Co}$, shows that all the compounds except the last one are tetragonal spinels. $\mathrm{ZnMnCoO}_{4}$ is however, shown to have a cubic structure (Bongers 1957 ; Kulkarni 1970). On the other hand, while $\mathrm{CuMnCoO}_{4}$ is expected to be cubic like $\mathrm{CuMnMeO}_{4}$ where $\mathrm{Me}=\mathrm{Cr}, \mathrm{Mn}$ and Fe, [Kulkarni and Mande (1970)] have shown it to be tetragonal. These structural contrasts in cobalt containing spinels have been associated with (Kulkarni 1970) the presence of $\mathrm{Co}^{+2}$ and $\mathrm{Mn}^{+4}$ ions in the lattice. We, therefore, thought it worthwhile to study $\mathrm{MgCoMnO}_{4}$ because magnesium, like zinc, exists only in the divalent state and has preference for the $A$ sites. An exhaustive survey of the literature on spinel indicates that this compond has not been studied. 


\section{Experimental}

\subsection{Preparation and identification}

The compound $\mathrm{MgCoMnO}_{4}$ was prepared by the oxide method (Economos 1955) by intimately mixing under acetone $\mathrm{Co}_{2} \mathrm{O}_{3}, \mathrm{Mn}_{2} \mathrm{O}_{3}$ and $\mathrm{MgO}$ of $\mathrm{AR}$ grade in proper molar proportions. The mixture was pressed into pellets of $1.0 \mathrm{~cm}$ diameter under 5000 p.s.i. using $5 \%$ polyvinyl acetate as a binder. The pellets were first slowly heated up to $300^{\circ} \mathrm{C}$ for about $3 \mathrm{hr}$ to evaporate the binder and finally fired in air at $900^{\circ} \mathrm{C}$ for $90 \mathrm{hr}$ in an electric furnace. They were, then, furnace-cooled at the rate of $100^{\circ} \mathrm{C} / \mathrm{hr}$. The $\mathrm{x}$-ray diffraction pattern was taken on Phillips diffractometer using filtered $\mathrm{MoK}_{\alpha}$ radiation. The formation of the compound was taken to be complete as the peaks due to reacting oxides were found to be absent in the diffractogram, thus indicating the existence of a single phase.

\subsection{Magnetic susceptibility}

The susceptibility measurements were carried out in the temperature range $80^{\circ} \mathrm{K}$ (liquid nitrogen) to room temperature using Faraday's method. The design of cryostat was similar to that described by Figgis and Nyholm (1959) with a few modifications. $\mathrm{HgCo}(\mathrm{CNS})_{4}$ was used as a calibrant. The diamagnetic contribution due to the tube and wire assembly was taken into account as only a efw milligrams of the compound was used.

\subsection{Electrical resistivity}

In order to determine the DC resistivity a thin layer of colloidal graphite was applied on the clean and flat parallel faces of the pellets, to provide good electrical contact. DC resistance of the pellet was determined in the temperature range $373^{\circ} \mathrm{K}$ to $873^{\circ} \mathrm{K}$ in steps of $20^{\circ} \mathrm{K}$ by applying a steady potential difference of $2 \mathrm{~V}$ across the sample and measuring the current with a microammeter. The potential difference across the sample was measured with a VTVM having 11 meg-ohm input resistance. The type of charge carrier was found out by the hot probe method.

\section{Results}

The $d$ values for various planes and their relative intensities measured from the heights of the peaks in the diffractogram are given in table 1 . The compound is found to have a tetragonal structure with $a=8.30 \mathrm{~A}$ and $c=8.46 \mathrm{~A}$.

The variation $\log \rho$ against $1 / T$ is linear showing that the well-known exponential law $\rho=\rho_{0} \exp (\triangle E / K T)$ is obeyed in the temperature range covered. The activation energy $\Delta E$ as calculated from the graph is $0.33 \mathrm{eV}$. The resistivity is of the order of $6 \times 10^{4} \mathrm{ohm}-\mathrm{cm}$ at room temperature and $2 \times 10^{1} \mathrm{ohm}-\mathrm{cm}$ at $873^{\circ} \mathrm{K}$. The hot probe test indicaies that the compound is $n$ type semiconductor. 
Table 1. Results of x-ray diffraction study of $\mathrm{MgCoMnO}_{4}$

\begin{tabular}{cccc}
\hline $\begin{array}{c}d \text { in A } \\
\text { (observed) }\end{array}$ & $\begin{array}{c}d \text { in A } \\
\text { (calculated) }\end{array}$ & $\begin{array}{c}\text { I/lo } \\
\text { (observed) }\end{array}$ & $\begin{array}{c}\text { Plane } \\
\text { (h k l) }\end{array}$ \\
\hline 4.83 & 4.82 & 10 & 111 \\
2.93 & 2.93 & 35 & 220 \\
2.51 & 2.51 & 100 & 311 \\
2.12 & 2.12 & 15 & 004 \\
2.05 & 2.07 & 20 & 400 \\
1.70 & 1.70 & 8 & 422 \\
1.60 & 1.60 & 26 & 511 \\
1.47 & 1.48 & 38 & 404 \\
1.46. & 1.47 & 24 & 440 \\
\hline
\end{tabular}

Tetragonal : $a=8.30 \mathrm{~A} \quad c=8.46 \mathrm{~A}$

The variation of $1 / \chi_{M}$ against $T$ is also linear indicating that the compound is paramagnetic in the temperature range investigated and obeys Curie-Weiss law $\chi_{M}=C_{M} /(T-\theta)$. The reciprocal molar susceptibilities $\left(\frac{1}{\chi_{M}}\right.$ at room temperature and $80^{\circ} \mathrm{K}$ are found to be $110.10 \times 10^{1} \mathrm{~mole} / \mathrm{emu}$ and $44.04 \times 10^{1}$ mole/emu. The observed Curie molar constant $\left(C_{M}\right)$ is 5.75 and the asymptotic Curie temperature is found to be $-160^{\circ} \mathrm{K}$.

\section{Discussion}

The possible valence structures for $\mathrm{MgCoMnO}_{4}$ are the following:

(i) $\mathrm{Mg}^{+2} \mathrm{Co}^{+3} \mathrm{Mn}^{+3} \mathrm{O}_{4}$ or (ii) $\mathrm{Mg}^{+2} \mathrm{Co}^{+2} \mathrm{Mn}^{+4} \mathrm{O}_{4}$.

It is well-known that $\mathrm{Mn}^{+3}\left(d^{4}\right)$ produces a prolate distortion of the oxygen octahedra about the $B$ sites. The compound $\mathrm{MgCoMnO}_{4}$ is expected to have the same cubic structure like $\mathrm{ZnCoMnO}_{4}$ since both zinc and magnesium exist only in the divalent state and have preference for the $A$ sites. However, the observed crystallographic results show that it is tetragonal with $c>a$. The observed symmetry can only be explained to be due to the presence of $\mathrm{Mn}^{+3}$, the JT ions on the $B$ sites. Hence the valence structure (ii) may be ruled out. The site distribution of cations was decided from the knowledge of site preference energies for $\mathrm{Mg}^{+2}\left(5.0 \mathrm{k} \mathrm{cal} / \mathrm{g}\right.$. at wt. - $A$ sites) and $\mathrm{Mn}^{+3}$ ( $3.1 \mathrm{k} \mathrm{cal} / \mathrm{g}$. at. wt. $-B$ sites) (Miller 1959). It is therefore reasonable to assume that $\mathrm{Mg}^{+2}$ ions are at the $A$ sites and $\mathrm{Mn}^{+3}$ ions on the $B$ sites. The situation does not change even if $\mathrm{Co}^{+3}$ ions are present in the structure because, like $\mathrm{Mn}^{+3}$, they also have a strong preference for the $B$ sites. The ionic structure for the compound can, therefore, be written as

$$
\mathrm{Mg}^{+2}\left[\mathrm{Co}^{+3} \mathrm{Mn}^{+3}\right] \mathrm{O}_{4}
$$

Our magnetic susceptibility data also confirms the first valence structure. The theoretical $C_{M}$ (spin only) values for the above two valence structures are 6.0 and 3.74 respectively. The observed $C_{M}$ value $(5.75)$ is more close to the 
theoretical $C_{M}$ value for $\left(\mathrm{Co}^{+3}+\mathrm{Mn}^{+3}\right)$ combination but much higher than the theoretical value of $C_{M}$ for the $\left(\mathrm{Co}^{+2}+\mathrm{Mn}^{+4}\right)$ combination. Thus the combination $\left(\mathrm{Co}^{+3}+\mathrm{Mn}^{+3}\right)$ is found to be more stable than $\left(\mathrm{Co}^{+2}+\mathrm{Mn}^{+4}\right)$ combination. In spinels, the large negative values of $\theta_{a}$ are indicative of stronger $B-B$ interactions as in $\mathrm{ZnMn}_{2} \mathrm{O}_{4}$ (Aiyama 1966), $\mathrm{MgMn}_{2} \mathrm{O}_{4}$ (Muramori and Miyahara 1960), $\mathrm{CoMn}_{2} \mathrm{O}_{4}$ (Boucher et al 1968). In these compounds the $B$ sites are occupied by $\mathrm{Mn}^{+3}$ ions indicating that the $\mathrm{Mn}_{B}{ }^{+3}-\mathrm{Mn}_{B}{ }^{+3}$ interactions are strong. On the other hand, in $\mathrm{ZnCo}_{2} \mathrm{O}_{4}$, where $A$ sites are occupied by the nonmagnetic ions $\mathrm{Zn}^{+2}$ like $\mathrm{MgCo}_{2} \mathrm{O}_{4}$ and $B$ sites are occupied by $\mathrm{Co}^{+3}$ ions, the small negative value of $\theta_{a}\left(-50^{\circ} \mathrm{K}\right)$ (Cossee 1956) shows that the $B-B$ interactions among $\mathrm{Co}^{+3}-\mathrm{Co}^{+3}$ ions are weaker. Similarly the small negative value of $\theta_{a}$ in $\mathrm{Co}_{3} \mathrm{O}_{4}$ (Roth 1964) is also suggestive of weaker $\mathrm{Co}_{B}{ }^{+3}-\mathrm{Co}_{B}{ }^{+3}$ interactions. In $\mathrm{MgCoMnO}_{4}$, the $A$ sites are occupied by the non-magnetic ions $\left(\mathrm{Mg}^{+2}\right)$ and hence $A-A$ interactions are absent. The value of $\theta_{a}\left(-160^{\circ} \mathrm{K}\right)$, suggests that the $\mathrm{Co}_{B}{ }^{+3}-\mathrm{Mn}_{B}{ }^{+3}$ interaction is weaker than $\mathrm{Mn}_{B}{ }^{+3}-\mathrm{Mn}_{B}{ }^{+3}$ interaction but stronger than $\mathrm{Co}_{B}+3-\mathrm{Co}_{B}{ }^{+3}$ interaction.

The observed ionic configuration suggests that this compound can be regarded as (i) a solid solution of $\mathrm{MgMn}_{2} \mathrm{O}_{4}$ and $\mathrm{MgCo}_{2} \mathrm{O}_{4}$ or (ii) $\mathrm{MgCo}_{2} \mathrm{O}_{4}$ substituted by $\mathrm{Mn}^{+3}$ ions or (iii) a $\mathrm{Co}^{+3}$ substituted $\mathrm{MgMn}_{2} \mathrm{O}_{4}$. In the absence of a detailed investigation of the electrical behaviour of $\mathrm{MgCo}_{2} \mathrm{O}_{4}$, it is rather difficult to apply the first and second idea in the present case. However, it is possible to explain the electrical behaviour of this compound by regarding it as $\mathrm{MgMn}_{2} \mathrm{O}_{4}$ in which some of $\mathrm{Mn}^{+3}$ ions have been substituted by $\mathrm{Co}^{+3}$ ions. The activation energy of this compound is $0.33 \mathrm{eV}$, with electrons as carriers. This is the same as the activation energy of $\mathrm{MgMn}_{2} \mathrm{O}_{4}(0.33 \mathrm{eV}$ ) which is also $n$ type (Kshirsagar and Sabane 1971). It is well-known that a slight substitution may alter the $\triangle E$ in spinels considerably (Jonker 1959). But in the present case, the substitution of $\mathrm{Mn}^{+3}$ by $\mathrm{Co}^{+3}$ ions on the $B$ sites has not altered the activation energy. The room temperature resistivity of $\mathrm{MgMnCoO}_{4}$ is also close to that of $\mathrm{MgMn}_{2} \mathrm{O}_{4}$ $\left(\sim 10^{5} \mathrm{ohm}-\mathrm{cm}\right)$ (Kshirsagar and Sabane 1971). This idea also explains well the lower value of axial ratio cla for $\mathrm{MgCoMnO}_{4}$ (1.02) than for $\mathrm{MgMn}_{9} \mathrm{O}_{4}(1.15)$ (Navrotskvy and Kleppa 1968) as $\mathrm{Co}^{+3}$ ion is non distortive and replacement of $\mathrm{Mn}^{+3}$ by $\mathrm{Co}^{+3}$ has reduced concentration of $\mathrm{Mn}^{+3}$ the $\mathrm{J}-\mathrm{T}$ ion, on the $B$ sites. Thus the structural, magnetic and electrical studies lead to the ionic structure as

$$
\mathrm{Mg}^{+2}\left[\mathrm{Co}^{+3} \mathrm{Mn}^{+3}\right] \mathrm{O}_{4}
$$

\section{Acknowledgement}

Thanks are due to the authorities of the Tata Institute of Fundamental Research, Bombay for permission to carry out some of the investigations. One of the authors (SGJ) wishes to thank the University Grants Commission for the award of a research fellowship. 


\section{References}

Aiyama Y 1966 J. Phys. Soc. Jpn. 211684

Bongers P F 1957 Magnetic susceptibility measurements of Zn-Mn spinels Ph. D. Thesis, Leiden University, Leiden

Boucher B, Buhl R and Perrin M 1968 J. Appl. Phys. 39632

Cossee P 1956 Red. Trav. Chim. 751089

Economos J 1955 J. Ceram. Soc. 38241

Figgis B N and Nyholm R S $1959 \mathrm{~J}$. Chem. Soc. 331

Jonker G H 1959 J. Phys. Chem. Solids 9165

Kshirsagar S T and Sabane C D 1971 Jpn. J. Appl. Phys. 10794

Kulkarni D K 1970 X-ray spectroscopic study of some spinels Ph. D. Thesis, Nagpur University, Nagpur

Kulkarni D K and Mande C 1970 J. Phys. D3 434

Miller A 1959 J. Appl. Phys. Suppl. $3024 \mathrm{~S}$

Muramori K and Miyahara S 1960 J. Phys. Soc. Jpn. 211684

Navrotsky A and Kleppa O J 1968 J. Inorg. Nucl. Chem. 30479

Roth W L 1964 J. Phys. 25507 